now reproduced (see Fig, 2), in order to give an opportunity of comparing it with the figure (Fig. 1) of the true $R$. sumatrensis.

In July last Mr. William Jamrach received a female two-horned rhinoceros from Singapore, which is said to have been captured in a pitfall near Malacca, and placed it on deposit in the Zoological Society's Gardens. On comparing it with the female previously received from Chittagong, it became at once apparent that the two animals belonged to distinct, though nearly allied, species. The Malaccan animal, although undoubtedly adult, is much smaller-nearly as much as one thirdthan that from Chittagong. The fringe of long hairs on the posterior rim of the naked ears, which is very conspicuous in the Chittagong animal, is not present in the Malaccan example, in which, however, the whole interior of the ears is filled with short hairs. The whole body of the Malaccan animal is covered with coarse granulations, which are hardly apparent in that from Chittagong. The tail of the Malaccan animal is shorter and nearly naked; in that from Chittagong it is longer and tufted at the extremity. The head of the former animal is much narrower than that of the latter, as is particularly apparent when the distance between the ears of each is examined from a front view, and there can be no doubt that the skulls of the two animals, whenever they can be compared, will exhibit marked differences in size and structure.

Under these circumstances the Council of the Zoological Society thought it would be advisable to add the second animal also to their living collection, and accordingly agreed to purchase it of $\mathrm{Mr}$. Jamrach for the sum of 600 l. Unfortunately it did not live long in the Society's gardens.

Upon reference to authorities upon the Sumatran Rhinoceros, which was first described by $\mathrm{Mr}$. William Bell in the Philosophical Transactions of the Royal Society for 1793, and afterwards by Sir. Stamford Raffles in this country and by Cuvier and other writers in France, it became evident that the Malaccan animal was the true $R$ hinoceros sumatrensis of authors. This would be presumably the case, because the Fauna of the Britsh settlement of Malacca is nearly identical with that of the adjacent island of Sumatra. The Chittagong animal, its northern representative, is therefore proposed to be called the Hairy-eared Rhinoceros (Rhinoceros lasiotis), from its peculiar ear-fringe of long hairs, which has been already spoken of. How far the Sumatran Rhinoceros extends north along the Malayan peninsula is not yet as-

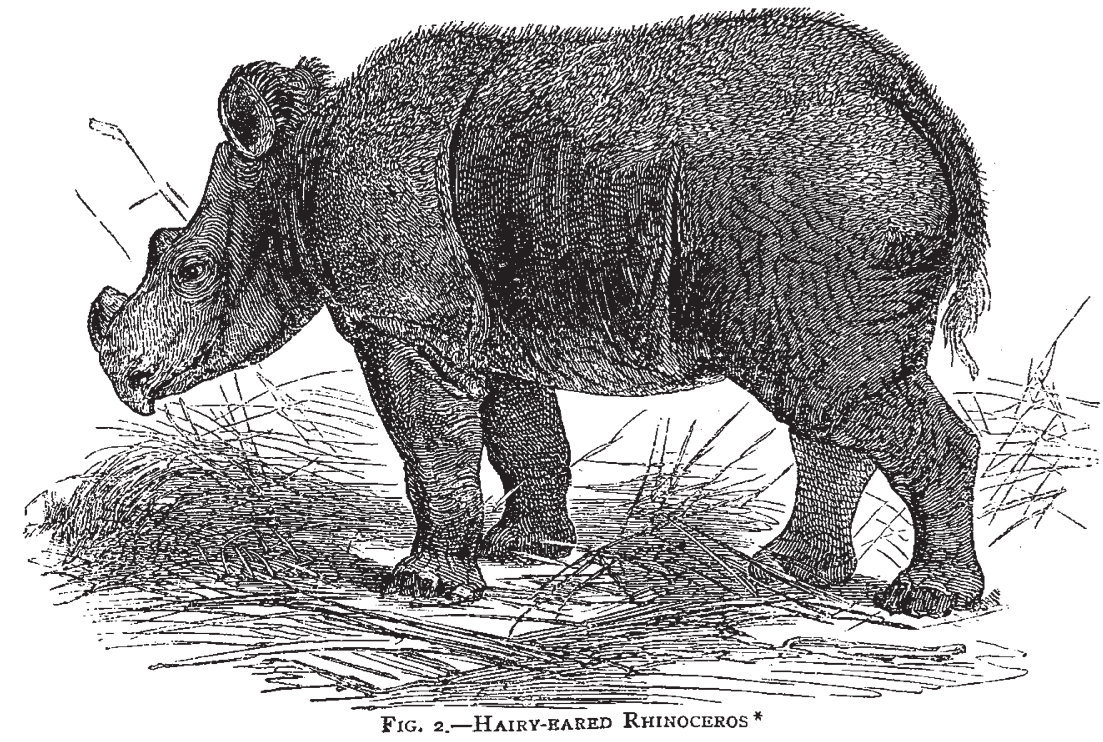

certained, because, although Two-horned Rhinoceroses are known to occur in several intermediate localities, it is uncertain to which of the two allied species they belong. The range of $R$. lasiotis is likewise quite a matter of un certainty at present, the animal being utterly unknown except from the individual in the Zoological Society's Gardens. But it is probable that it extends into Assam, where there are reports of the occurrence of a Two-horned species of Rhinoceros.

Besides the two Rhinoceroses just spoken of, two other specimens of Asiatic Two-horned Rhinoceroses have been imported alive into Europe since the commencement of the present year. One of these was purchased by an agent of one of the American travelling menageries, and exported to New York; the other is now in the gardens of the Zoological Society of Hamburgh. Both these animals are said to have been received from Singapore, and to resemble exactly the Malaccan animal in London. of the second a figure and description have been published in a Hamburgh journal (Der Reform); which shows that the animal is certainly the true $R$. sumatrensis.

* It should be stated that this figure is drawn on a smaller scale than that of the Sumatran Rhinoceros, the latter being really the smaller animal.-ED.
By the addition of these two animals to their Menagerie the Zoological Society have now been able to exhibit side by side specimens of four (out of the six certainly known) living species of Rhinoceros-a wonderful advance, when we consider that a very few years ago the Indian $R$ hinoceros unicornis was alone known in Europe in a living state. The two species remaining to be obtained are the Javan Rhinoceros (Rhinoceros sondaicus), a smaller representative of the One-horned Indian, and the White Rhinoceros of Africa (Rhinoceros simus). It need hardly be added that any correspondents of NATURE who may be able to assist in supplying these desiderata will not only be conferring a benefit on science, but will be liberally dealt with by the Council of the Society.

P. L. S.

\section{RECENT FALLS OF METEORITES IN FRANCE AND ITALY}

THE French Academy of Sciences has recently received several important and interesting accounts of the fall of two or three meteoric masses in France and Italy. On the 23 rd of July, about half-past five on a still afternoon, with a perfectly clear sky and a bright sun, a 
violent report, followed by a rumbling noise, was heard in the commune of Lancé, canton of St. Arnaud(Loir-et-Cher). On the following day it was ascertained that the noise had been heard over a wide area of country, and had caused much uneasiness; and a letter arrived from a landowner of Lile-Bouchard, announcing that he had seen a "fiery lance" shooting across the sky in a direction from S.W. to N.E. with great swiftness. Whilst on its way its point appeared to split, giving rise to two meteors, which continued their way parallel to each other for some distance. Another observer south of Tours had also seen them, and described them as having the shape of a bottle, and being of an orange colour. M. De Tastes, who communicated the first account to the Academy, on proceeding to St. Arnaud, was fortunate enough to learn that one of these meteorites had been seen to fall near Lance, and he was also successful in finding it. Its weight was 47 kilogrammes (about ro3 lbs.), and it had penetrated to a depth of 1.40 metres (about $5 \mathrm{ft} .9$ in.). On being removed, it broke into three pieces. Of the second meteorite nothing was heard for some time, but it was ultimately found at a place called Pont-Loisel, about 12 kilometres ( $7 \frac{1}{2}$ miles) to the south-west of the place where the other had fallen; and an account of it is given to the Academy by $M$. Daubrée. It is of exactly the same mineralogical character as the one first found, thus showing it originally belonged to it, but its weight is only 250 grammes, and it had only penetrated to the depth of about half a metre. On ascertaining the course of the meteorite, it was found that this, the smallest portion, had fallen first, and that the larger one had continued its course for some distance farther. In this respect it resembled the meteorite which fell on March 14, 1864, near Orgueil (Tarn-et-Garonne), in which the smallest portion, weighing about 15 grammes, first fell, and then the heavier one, weighing 40 grammes.

M. Daubrée has recently analysed the meteorite, and his results are somewhat remarkable. The largest piece is of an unequal spheroidal shape, with a rounded surface ; it is covered all over with a crust, probably caused by the incandescence and superficial fusion. In appearance the fracture is black, and almost basaltic looking, showing a globular structure and numerous small spheroidal grains. Here and there small metallic grains are to be seen, yellow in colour, like iron bisulphide, these and other metallic-looking grains showing much better when the surface is polished. Its specific gravity was 3.80. Treated with water, a very small quantity of chloride of sodium dissolved out, and $M$. Daubrée remarks that this is not the first time that this salt has been found in meteorites; and he brings forward evidence to show that it could not have been derived from the soil in which the meteorite was buried, but that it must have formed part of it when it fell. No traces of any salts of potash, nor of any sulphates or hyposulphates could be found. Dissolved in nitric acid, a silicate was found, which was proved to consist chiefly of magnesium and protoxide of iron, and there was an undissolved residue, part of which was colourless, the remainder dark black. By means of spectrum analysis, copper was thought to be recognised; but calcium, barium, and strontium were shown to be absent. No carbon was found; but, as usual, cobalt and nickel accompanied the iron. The following is the complete analysis :-

Free iron combined with nickel and cobalt...

Iron and other metals combined with sulphur $9.0 \%$ | $7: 81$

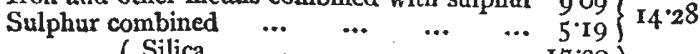

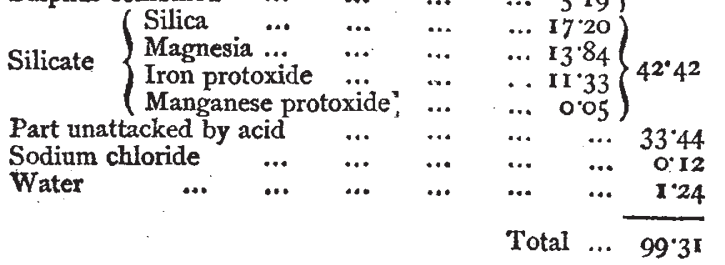

In its general appearance this meteorite resembled that which fell July I I, I 868, at Ornans (Doubs), but differs from it in the absence of free iron oxide. Other characters distinguish it from the black meteorites of Rutlam (East Indies) and that of Tadjera, near Setif (Algeria)

Several meteorites have also lately been seen in Italy, which have excited considerable attention. One on the evening of the 8th of August, at about eight minutes past I I, was seen at Rome, and also at Velletri, Naples, and Palermo. A more interesting one than this was seen near Rome, at about 5.15 mean time, on the morning of the 3 Ist of August, of which Padre Secchi has communicated a long account to the Academy. At about 5.15 in the early morning on that day a globe of fire, well marked and a little red in colour, appeared on the horizon towards the S.S.W., proceeding towards the N.N.E. Its progress was at first slow, but this gradually increased, and it left behind it a luminous train like a cloud lit up by the sun. When it had reached its highest point, E.N.E. from Rome, it suddenly expanded and took the shape of a cone having its base rounded in front; it brightened up greatly and finally disappeared. Three or four minutes after its disappearance a tremendous detonation was heard, which caused, in many places, houses and glass to rattle. This explosion was dull, different to thunder, and resembling more the explosion of a mine, and was followed by a rolling sound like file-firing. This noise was heard by Padre Secchi himself, but he did not see the globe of fire. The vapour-like residue left by the meteorite was at first in the shape of a long straight line, but it soon enlarged, and turned about like some great serpent until it disappeared about ten or fifteen minutes afterwards.

This meteor was also seen a long way from Rome, at Viterbo and at Veroli, but the noise of the explosion in each place was equally strong, and caused houses and glass to rattle. A small piece of the meteorite which fell near him was picked up by a curé soon after the explosion at Affile, near to Subiaco, where the ball of fire and the noise of the explosion were well seen and heard. The fragment has been recognised as a piece of a very ferruginous meteorite, very hard, and covered over with a crust. It is also said that at Orvinio "black stones" have been picked up. But this is not all. A wellinstructed farmer had assured me, says Padre Secchi, that the same morning at 3.30, being at Casale S. Lorenzo, near to Porto d'Anzio, whilst he was waiting for his men, he saw out at sea, at an elevation of about $30^{\circ}$ or $40^{\circ}$, a mass of fire or light like a fire, of a round form, apparently fixed, and which could not be confounded either with a lighthouse or any fire at sea. The position of this fire was exactly the same as that from which the meteorite afterwards appeared, and which he saw very distinctly in the heavens at 5.15 , when he was so much struck with the coincidence of direction that he judged it to be the same mass of fire which had then reached the earth. The size of the meteorite at its first appearance and at the moment of explosion is represented as little less than the diameter of the moon. The extreme distances at which it was seen are 150 kilometres (93 miles) apart.

Another meteorite was seen at Subiaco on August 6, at four in the morning; and another near Ascoli on the 18th of September. J. P. E.

\section{DARDANELLES AND BOSPHORUS UNDER- CURRENT}

$T \mathrm{~T}$ will be in the recollection of such of your readers as have followed the discussion on Ocean Currents, that I ventured nearly two years ago* to predict the existence of an Under-current of dense Egean water into the Black Sea, "on the double ground of $a$ priori and $a$ posteriori necessity; "-that is, I affirmed it to be a necessary result of the excess of Specific Gravity in the water 